\title{
Characterization of post FR treatedtextile materials: A comparative study
}

See end of the paper for authors' affiliations Archana Bahuguna

Department of Textile and Apparel Designing, College of Rural Home Science, University of Agricultural Sciences, Dharwad (Karnataka) India

Email : archana5337bahuguna@ gmail.com
ABSTRACT : Cotton and polyester fabrics were subjected to Atmospheric Pressure Plasma (APP) followed by Flame Retardant (FR) treatment using dielectric barrier discharge plasma with He- $\mathrm{O}_{2}$ gas mixture by padding mangle; dried and cured on hot air stenter. The main aim of the study was to assess the effect of plasma-FR treatment on fibre topography, structural and functional properties.Surface topography of treated test samples assessed under SEM and revealed about surface erosion of both the fibres through pictorial presentation. Positive enhancement not only in structural properties of FR finished fabrics viz., cloth count, thickness, GSM and dimensional stability but also the flame retardancy of cotton and polyester were noticed. Further, the qualitative improvements induced due to plasma-FR treatment were found to be sustainable on multiple washes. Thus, it is concluded that APP as a pre-treatment increases the fixation of FR agent into the etched fibre surface and induces sustainability of finish at greater levels.

KEY WORDS: Cotton, Flame retardant (FR), Helium-Oxygen plasma treatment, Polyester, Surface topography

- HOW TO CITE THIS PAPER : Bahuguna, Archana and Naik, Shailaja D. (2018). Characterization of post FR treatedtextile materials: A comparative study. Asian J. Home Sci., 13 (1) : 289-294, DOI: 10.15740/ HAS/AJHS/13.1/289-294. Copyright@ 2018: Hind Agri-Horticultural Society. 